\title{
Multi Objective Optimization on the Design of A Forced Circulation Solar Hot Water System
}

\author{
Qing-long KONG \\ Department of Mechanical Engineering \\ Beijing Institute of Petrochemical technology \\ Beijing 102617, P.R. China \\ Zheng CHANG* \\ Department of Mechanical Engineering \\ Beijing Institute of Petrochemical technology \\ Beijing 102617, P.R. China \\ e-mail: changzheng@bipt.edu.cn
}

Yuan LI

Opto - Mechatronic Equipment Technology Beijing Area

Major Laboratory

Beijing Institute of Petrochemical technology

Beijing 102617, P.R. China

\author{
Feng-xiang ZHU \\ Department of Mechanical Engineering \\ Beijing Institute of Petrochemical technology \\ Beijing 102617, P.R. China \\ Yin-qi FENG \\ Opto - Mechatronic Equipment Technology Beijing Area \\ Major Laboratory \\ Beijing Institute of Petrochemical technology \\ Beijing 102617, P.R. China \\ e-mail: fengyinqi@bipt.edu.cn.
}

\begin{abstract}
According to the purpose of energy saving and low cost, a set of optimization design method is put forward for designing a forced circulation solar hot water system which can meet the need for all hot water loads. A digital model of solar water heating system is constructed in which the relationship between guarantee rates of solar energy and total system costs is considered. And multi-objective optimization model for the system is established. Using MATLAB genetic algorithm toolbox the objective model is optimized and solved. Pareto no dominated solution sets for multi objective function are analyzed, and the optimum area of its collector was obtained.
\end{abstract}

Keywords- Solar water heating system; Multi-objective optimization; Genetic algorithm; Solar collector area; Solar energy guarantee rate

\section{INTRODUCTION}

The rapid economic development has brought two major crises to human society. One is a crisis of fossil energy shortage, the other is an ecological crisis of environmental pollution by burning fossil energy. For facing these two crises, clean, renewable solar energy has been widely used in the world. However, at present solar water heating systems used in the urban and rural to meet the hot water needs for all-weather are still relatively high on initial investment costs and difficult to run at low operating costs.[1] Forced circulation solar hot water systems, with their advantages such as its easy anti-freezing, anti-corrosion, anti-fouling and low costs on civil construction as their storage tanks are flexible layout is widely used in schools, hotels and other users who are using large-scale solar hot water systems.
As the structures of forced circulation solar hot water systems are big and complex, their initial investments are much large. And because of their large thermal powers, these systems need large auxiliary heating powers to be designed to meet all weather hot water needs.2 System's energy comprehensive utilization could be significantly improved with same hardware if solar thermal power and electric heating power are designed to meet the economic optimization. And the total investment of the project and the system operation costs can be significantly reduced while satisfying all-weather water demand on the system.[3,4]

Non-optimal design for auxiliary heating power to meet all-weather hot water load demand in current forced circulation solar hot water system s result in a large waste of energy and the system's solar energy utilization rate is reduced. Or the area of its heat exchanger is designed too large to cause $\mathrm{d}$ high initial investment cost.5 In this paper, a multi-objective optimization design method for a forced circulation solar water heating system is proposed based on low-cost and high-profit economic design principle. The system structure optimization is designed by matching auxiliary electric heating power with solar thermal power economically. The optimal structure design could achieve the lowest overall economic cost (initial investment and operating costs) for the system to meet all-weather hot water load demand.

\section{MULTI OBJECTIVE OPTIMIZATION MATHEMATICAL MODEL OF THE SYSTEM}

The structure of typical forced circulation solar hot water system is shown in Figure 1. 


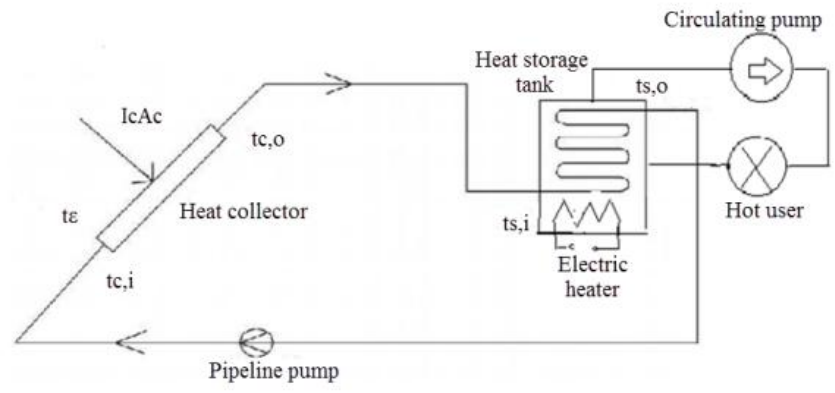

Figure 1. Structure of a forced circulation solar hot water system

A solar energy guarantee rate $f$ of the system is a percentage of solar energy in total system load. When the system load L is certain without changing, the system guarantee rate $f$ values are changed with the different collector area A values, that could make the annual savings of the solar system different as well.

Solar energy guarantee rate $\mathrm{f}$ is actually theratio of effective heat Qu from the Sun and heat loads required [6] in the system, namely:

$$
f=\frac{Q_{u}}{L}=\frac{F_{R}}{L} \int\left[I_{T}(\tau \alpha)-U_{L}\left(T_{i}-T_{\alpha}\right)+d_{t}\right]
$$

where, $F_{R}$ is a heat transfer factor of the collector; $A$ is collector area, $\mathrm{m}^{2}$; IRis total radiation irradiated on the collector surface, $\mathrm{J} / \mathrm{m} 2 \bullet \mathrm{h}(\mathrm{kcal} / \mathrm{m} 2 \bullet \mathrm{h}) ; \tau$ is the transmission coefficient of the collector cover system; $\alpha$ is absorption coefficient of the absorber surface of the collector; UL is heat loss coefficient of the collector, $\mathrm{W} / \mathrm{m}^{2} \cdot{ }^{\circ} \mathrm{C}\left(\mathrm{kcal} / \mathrm{m}^{2} \bullet \mathrm{h}\right) ; \mathrm{Ti}$ is fluid temperature at inlet of the collector, ${ }^{\circ} \mathrm{C}$; $\mathrm{T} \alpha$ is outdoor air temperature, ${ }^{\circ} \mathrm{C} ; \Delta \mathrm{t}$ is the time period in discussed, $\mathrm{h}$. The sign "+" in the parentheses indicates that only the positive value is taken into account. Only when the solar energy absorbed by the collector is greater than the heat dissipated to the surrounding environment, the pump is turned on to operate the system.

The formula for annual cost of the system is [1]:

$$
\begin{gathered}
P=K P_{1} A+C \\
K=\frac{i(1+i)^{n}}{(1+i)^{n}-1}
\end{gathered}
$$

Where $\mathrm{P}$ is annual cost, yuan; $\mathrm{P}_{1}$ is the price of solar collectors, yuan $/ \mathrm{m}^{2} ; \mathrm{K}$ is a recovery factor of capital; $\mathrm{C}$ is the cost of electric power consumption on auxiliary heat, yuan; $\mathrm{i}$ is annual interest rate.

The area of the solar collector is directly related to the guarantee rate of the solar energy, and their relationship can be expressed by the following formula:

$$
f=G_{j} \eta_{j} A / Q_{j}
$$

When the solar energy guarantee rate is $100 \%$, the solar energy supply heat can fully meet hot water loads, and there is no need to use electric auxiliary heat. Then the critical collector area in jth month:

$$
A_{j}=Q_{j} / G_{j} \eta_{j}(j=1,2,3, L, 12)
$$

Annual cost $\mathrm{P}$ as $\mathrm{A}$ function of the collector area A can be established [3]:

$$
P=K P_{1} A+\sum_{j}\left(\frac{P_{2}}{36 \eta_{2}}\right)\left(Q_{j}-G_{j} \eta_{j} A\right)(j=1,2,3, L, 12)
$$

\section{REALIZATION OF MULTI OBJECTIVE SYSTEM OPTIMIZATION DESIGN}

The most multi objective optimization design to an object is that there are a number of important parameters in an objective function selected in design processes, but their advantage values cannot be taken at the same time. The optimal value of the objective function could be obtained only when each parameter is its best value with some sort of compromised implementation methods. The multi-objective optimization design of a forced circulation solar water heating system is based on the GA toolbox of MATLAB commercial software, which is realized by genetic algorithm.[7]

Initial parameters are set as following: the size of initial population is 100 , and the number of iterations is 100 . The crossover probability is set to be 0.8 and the mutation probability is 0.01 .

Minimum values of electric heating power consumption rates and annual costs of a hot water system are obtained by solving two objective functions on the platform of MATLAB using genetic algorithm toolbox. The speed of convergence of optimization functions is tracked.

Although the number of process iterations is set to 100 , it is clear that after 10 iterations results converge rapidly as shown in Fig. 2. 


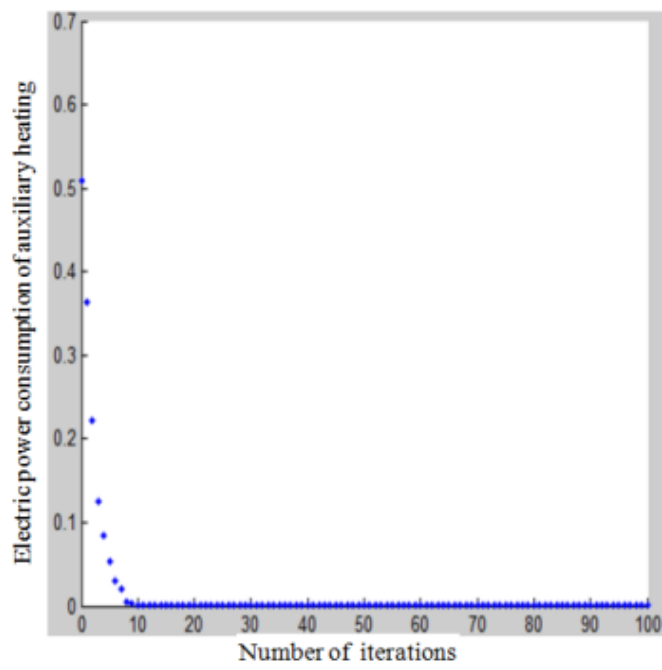

(a)

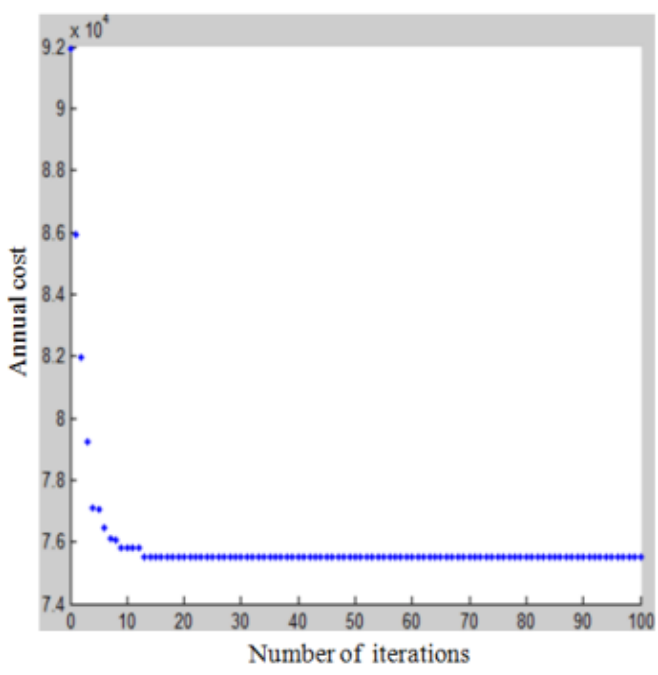

(b)

Figure 2. Optimization processes of power consumption rates with electric auxiliary heating and the system annual cost function

According to the first objective function, the optimal collector area is $506 \mathrm{~m}^{2}$. And the optimal collector area calculated from the second objective function is $473.822 \mathrm{~m}^{2}$. Obviously, the results of these two objective functions are inconsistent. In other words, when $506 \mathrm{~m}^{2}$ is taken to be the collector area, the solar energy guarantee rate in a year is $100 \%$, but the cost in value will be a slight increased. When $473.822 \mathrm{~m}^{2}$ is taken as the collector area, the annual cost will be the smallest, but the solar energy guarantee rate cannot reach $100 \%$.So in practical application, according to different requirements, there will be a choice of compromise between the solar energy guarantee rate and the cost value. Considering the optimal solution sets of two objective functions, we can see that the collector area is better between $506 \mathrm{~m}^{2} \sim 473.822 \mathrm{~m}^{2}$. From the range the Pareto nondominated solution set 4 is selected, as shown in Fig.3.

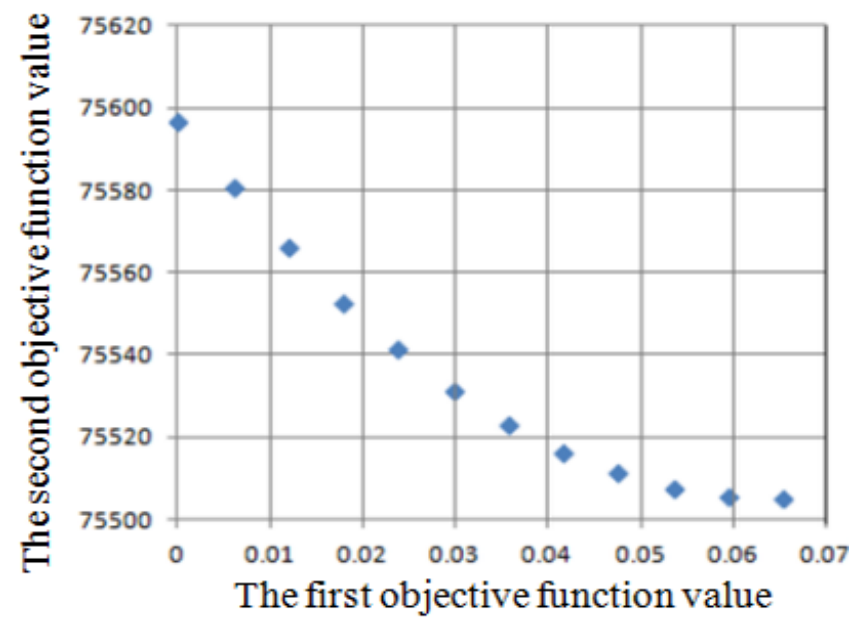

Figure 3. Distribution of Pareto non- dominated solutions for multi objective optimization

It can be seen from Fig. 3 that the cost value of the system decreases with the increase of the electric power consumption rate, that is, the annual cost decreases with the decrease of the solar energy guarantee rate. For nondominated solutions of multi objective Pareto distribution, when non-dominated solutions closer to the origin of coordinates, the more it to meet the actual requirements. Set the origin of coordinates as $(0,75000)$. Then non-dominated solutions closest to the coordinate origin are the optimal solutions of the multi objective function.

In order to obtain the optimal solutions of the multiple objective function, the first objective function value and the second objective function value are obtained and to be fit by a curve using MATLAB. And the fitted curve equation is:

$$
P=22666 \Phi^{2}-2889 \Phi+75598
$$

The shortest distance of the curve to the origin is a straight line. According to Figure 3, the straight line's equation can be drawn as:

$$
P=\frac{75520-75500}{0.01-0} \Phi+75500=2000 \Phi+75500
$$

From equations (7) and (8), it is solved that

$$
\Phi=0.02236
$$

When it is substituted into equations (7) and (2), it will be obtained that

$$
A=495 m^{2}
$$

In summary, optimization collector area is $495 \mathrm{~m}^{2}$, solar energy assurance rate is $97.8 \%$, and the value of an annual cost is 75545 yuan. 


\section{CONCLUSION}

In order to improve the comprehensive utilization rate of a solar hot water system and reduce the costs of initial investment and operation system, the optimization of the solar hot water system is analyzed, and a multi-objective optimization model is established. With the increase of the area of the system collector, the system solar energy guarantee rate increases, and the cost of initial investment on the system will increase as well. The solar energy guarantee rate model and the annual cost numerical model are established for solving this problem. Using the MATLAB genetic algorithm toolbox, the calculation is optimized. By analyzing the Pareto non dominated solution sets of the multi objective function, the optimal collector area is obtained.

\section{ACKNOWLEDGMENT}

This work is financially supported by a 2015 grant (KM201510017009) from Science Research Development Program of Beijing Education Council, P.R. China

\section{REFERENCES}

[1] Lei Cheng, Qi Tian, Optimization of Solar-Collector Area from the Angle of Economy, Shang Xi Energy and Conservation.44(2010).

[2] Kai Zhang, Selection of auxiliary heat source of solar heating system and Discussion on, Heating and Cooling, 46(2012).

[3] Zinian He, Solar thermal utilization,1th edn (China University of Science and Technology Press,(2009).

[4] Shiming Zhao, Feng Gao, Study on design of heat storage tank and auxiliary heat source in solar domestic hot water system, Water Supply and Drainage, 45,77(2009)

[5] J P Chou, The effect of non-uniform fluid flow distribution of the thermal performance of solar collector. Solar Energy.29,487(1982) .

[6] Z. Chang and L. Jia, Research on Numerical Simulation of Thermodynamic Performance in Forced Circulation Solar Water Heating System, Proc. Of 2011 Int. Conf. on Mechatronics \&Intelligent Materials, Lijiang, China.

[7] Ming Zhou, Shudong Sun, Principle and application of genetic algorithm. (National Defense Industry Press,1999). 